Medical Research Program, Consultant for: Boehringer-Ingelheim, M. Mayes Grant/research support from: U.S. National Institutes of Health-National Institute of Arthritis and Musculoskeletal and Skin Diseases, U.S. DOD Peer Reviewed Medical Research Program, Consultant for: Boehringer-Ingelheim, Genentech, Astellas, Mitsubishi-Tanabe, O. Distler Grant/research support from: Actelion, Bayer, Boehringer Ingelheim, Mitsubishi Tanabe Pharma, Roche, Consultant for: Actelion, Bayer, Biogenldec, Boehringer Ingelheim, ChemomAb, espeRare foundation, Genentech/Roche, GSK, Inventiva, Italfarmaco, Lilly, medac, Medlmmune, Mitsubishi Tanabe Pharma, Pharmacyclics, Novartis, Pfizer, Sanofi, Sinoxa, UCB

DOI: 10.1136/annrheumdis-2018-eular.5077

\section{THU0396 COMBINED POSITRON EMISSION TOMOGRAPHY AND MAGNETIC RESONANCE IMAGING FOR THE ASSESSMENT OF SYSTEMIC SCLEROSIS GASTROINTESTINAL INVOLVEMENT}

1,2S.-A. Ng, S. Marchesseau ${ }^{3}$, Y. Wang ${ }^{4}$, J. Schaefferkoetter ${ }^{3}$, W. $\mathrm{Xie}^{5}$, D. $\mathrm{Ng}^{5}$, J. Totman $^{3}$, A.H. Low ${ }^{1,2},{ }^{1}$ Rheumatology and Immunology, Singapore General Hospital; ${ }^{2}$ Duke-National University of Singapore; ${ }^{3}$ Clinical Imaging Research Center, $A^{*} S T A R$ and National University of Singapore; ${ }^{4}$ Gastroenterology and Hepatology; ${ }^{5}$ Nuclear Medicine and PET, Singapore General Hospital, Singapore, Singapore

Background: The gastrointestinal (Gl) tract is affected in $90 \%$ of patients with systemic sclerosis (SSc), a disease characterised by excessive fibrosis. Baseline Gl involvement is an independent predictor of 2 year mortality in patients with early diffuse cutaneous SSc. There is an urgent need to develop non-invasive methods of assessing SSc GI involvement for early diagnosis and monitoring. Novel non-invasive tools such as fluorodeoxyglucose-positron emission tomography (FDG-PET) and magnetic resonance imaging (MRI) have been used in oncology. Development of a new MRI sequence, T1 MOLLI (modified look-locker inversion recovery) mapping, has been used in cardiac imaging for detection and quantification of diffuse fibrosis.

Objectives: In this pilot study comparing SSc patients with healthy controls, we investigated whether FDG-PET-MRI is able to detect fibrosis and inflammation associated with SSc GI tract involvement.

Methods: We recruited 16 patients fulfilling the 2013 ACR/EULAR criteria for SSc and 15 healthy age-matched (within 5 years) controls. Severity of Gl involvement was determined by the total Gastrointestinal Tract score (GIT, from University of California Los Angeles Scleroderma Clinical Trials Consortium).

All subjects fasted 6 hours prior and had non-spicy low-residue diet 3 days prior. Subjects were injected with FDG $(6 \mathrm{mCi}) 1$ hour prior and $10 \mathrm{mg}$ hyoscine butylbromide (to reduce peristalsis) immediately before scanning. Breath-hold native T1 MOLLI mapping was acquired. FDG uptake was quantified by specific uptake value (SUV). All SSc patients and 5 controls underwent PET-MRI protocol. The remaining 10 controls only had MRI scanning. Student t-test was performed and statistical significance was taken to be $p<0.05$.

Results: Demographics and clinical features of our study cohort are shown in table 1. Mean T1 values on MRI for the large and small bowels were significantly higher in SSc patients than healthy controls (large bowel: $1113 \pm 189 \mathrm{~ms}$ vs 856 \pm 182 ms respectively, $p=0.0006$; small bowel: $1331 \pm 246$ ms vs $1169 \pm 123 \mathrm{~ms}$ respectively, $\mathrm{p}=0.0296$ ), indicating the presence of Gl fibrosis.

Mean PET SUV values for the large bowels were also higher in SSc patients than healthy controls $(1.12 \pm 0.23$ vs $0.82 \pm 0.23$ respectively, $p=0.0217)$.

Abstract THU0396 - Table 1. Demographics and clinical features

\begin{tabular}{lcc}
\hline & $\begin{array}{c}\text { SSc patients } \\
(\mathrm{n}=16)\end{array}$ & $\begin{array}{c}\text { Controls } \\
(\mathrm{n}=15)\end{array}$ \\
\hline Limited/Diffuse SSc, $\mathrm{n}$ & $11 / 5$ & $\begin{array}{c}\text { Not } \\
\text { applicable }\end{array}$ \\
& & $11(73.3 \%)$ \\
Female, $\mathrm{n}(\%)$ & $14(87.5 \%)$ & $45.3 \pm 14.4$ \\
Age, years & $49.2 \pm 13.9$ & Not \\
Mean disease duration from Raynaud's phenomenon & $6.1 \pm 7.3$ & $\begin{array}{c}\text { applicable } \\
\text { Not } \\
\text { onset, years }\end{array}$ \\
$\begin{array}{l}\text { Mean disease duration from non-Raynaud's phenomenon } \\
\text { onset, years }\end{array}$ & $6.6 \pm 7.4$ & applicable \\
Mean GIT score & $0.43 \pm 0.31$ & 0 \\
\hline
\end{tabular}

Conclusions: MRI T1-MOLLI mapping demonstrated evidence of bowel fibrosis in SSc patients. FDG-PET showed increased large bowel inflammation in patients. FDG-PET-MRI may potentially be a useful diagnostic and monitoring tool for SSc GIT disease.

Disclosure of Interest: None declared

DOI: 10.1136/annrheumdis-2018-eular.4410

\section{THU0397 \\ THE PROGNOSTIC VALUE OF AUTOANTIBODIES IN SYSTEMIC SCLEROSIS AND A TWO-YEAR FOLLOW-UP OF FORCED VITAL CAPACITY}

A.A.A. Mohamed, M. Hassanien. Rheumatology and Rehabilitation, Assiut University, Assiut, Egypt

Background: Systemic sclerosis (SSc) is a connective tissue disease involving the skin and internal organs of the body. Affection of the lungs and the vascular system significantly increases the morbidity and mortality. Controlling disease progression represents a challenge in clinical practice.

Objectives: We aimed to address prognostic factors of disease activity and study the progress of interstitial lung disease (ILD) under conventional disease modifying anti-rheumatic drugs (DMARDs) therapy.

Methods: Data of SSc patients (limited or diffuse) followed up in the Rheumatology Department Clinics throughout the past 2 years were collected for a retrospective study. The positivity of Antinuclear (ANA), Anti-centromere (ACA) and Anti-Scl70 antibodies was gathered from patients' data. Disease activity was assessed by the European Scleroderma Study Group (EScSG) activity index. Forced vital capacity (FVC) was used to mark the progress of ILD. Friedman and Wilcoxon signed rank tests were used for comparison of paired data as appropriated. Mann-Whitney $\mathrm{U}$ test, Kruskal-Wallis test and Chi-Square test were used to compare between two or more groups.

Results: The data of 42 SSc patients (59.5\% limited SSc and $40.5 \%$ diffuse SSc) with a mean age $40 \pm 12$ years were enrolled. $83.3 \%$ of the patients showed ANA positivity. ACA was positive in $28.6 \%$ of the patients and Anti-Scl70 in $23.8 \%$ while $47.6 \%$ of the patients were negative for both. DMARDs were indicated according to organ involvement, and changes were made according to breakthrough events. Low scores of EScSG were noticed in the ACA +ve group compared to intermediate scores in the Scl70 +ve group and high scores in the negative group at baseline $(p=0.082)$ and 24 month follow-up $(p=0.045)$. The frequency of pitting digital ulcers at baseline was lowest in the ACA +ve group compared to the highest frequency in the negative group $(p=0.026)$, however, there was no difference between the groups at the 24 month follow-up. ANA did not affect the activity throughout the studied period. Follow up of FVC in the two years with different DMARDs is illustrated in figure 1. Patients followed on methotrexate (MTX) after cyclophosphamide (CYC) or mycofenolate (MMF) had raised FVC ( $p=0.033$ and $\mathrm{p}=0.054$ respectively) comparable to azathioprine (AZA) after CYC or MMF ( $\mathrm{p}=0.031$ and $\mathrm{p}=0.27$ respectively).

Follow up of FVC in SSC

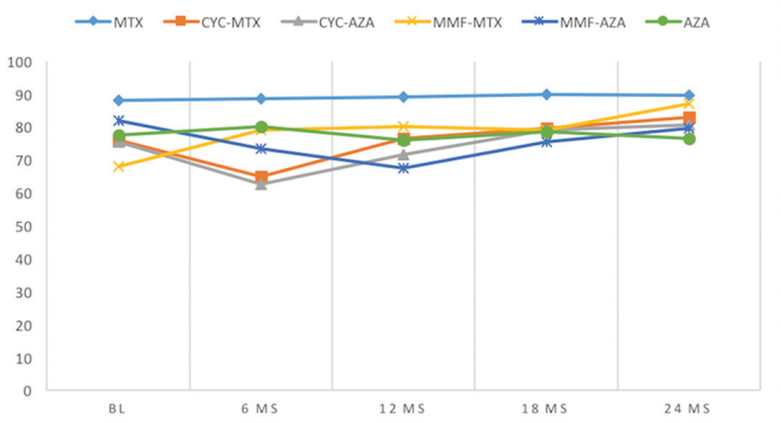

Conclusions: ACA is proposed to be a marker of low disease activity and good response to therapy. Despite the risk of inducing ILD, MTX maintained a favourable effect on FVC throughout a follow-up period.

Disclosure of Interest: None declared

DOI: 10.1136/annrheumdis-2018-eular.4113

\section{THU0398 UNEXPLAINED IRON DEFICIENCY IS FREQUENT IN SYSTEMIC SCLEROSIS}

A. Sari, A. Gill, S.I. Nihtyanova, V.H. Ong, C.P. Denton. Rheumatology, Royal Free Hospital, University College London, London, UK

Background: Prevalance of iron deficiency (ID) in systemic sclerosis (SSc) is unclear and can occur related to several causes.

Objectives: This cross sectional study aims to analyse association between ID and disease characteristics in SSc patients who does not have an overt cause for ID.

Methods: We identified 227 consecutive SSc patients who had iron laboratory studies (serum iron, total iron binding capacity and ferritin) with concurrent full blood count and serum C-reactive protein (CRP) measurement between May 